\title{
Aurotriquia adquirida em um canino da raça schnauzer
}

\author{
Acquired aurotriquia in a schnauzer dog
}

\section{Mariana Isa Poci Palumbo ${ }^{\mathrm{I} *}$ Luiz Henrique de Araújo Machado ${ }^{\mathrm{I}}$ Rafael Torres Neto ${ }^{\mathrm{I}}$}

\begin{abstract}
Alterações adquiridas na coloração da pelagem RESUMO de cães são raras. Schnauzers miniaturas podem apresentar desenvolvimento idiopático de coloração dourada do pelame, primariamente do tronco, chamada de aurotriquia. O presente trabalho relata a ocorrência de aurotriquia em um cão da raça schnauzer, de três anos de idade, sendo esse o primeiro relato de caso de aurotriquia em schnauzer no Brasil. Por se tratar de alteração de rara ocorrência, torna-se necessária maior atenção a características raciais e um melhor exame físico e anamnese, mesmo se tratando de alteração considerada meramente de fenótipo, pois existem as alterações de coloração bem piores, ligadas a doenças de prognóstico.
\end{abstract}

Palavras-chave: dermatologia, cães, schnauzer e pelos.

\section{ABSTRACT}

Coat color changes in adult dogs are rare. Miniature schnauzers can development golden hair coat color, primarily in the trunk, called aurotriquia. This paper reports the occurrence of aurotriquia in a schnauzer, three years old, being this the first case report of aurotriquia schnauzer in Brazil. Due to its rare occurrence there is a need for greater attention to racial characteristics and a better physical examination and medical history, Despite, being only a change in the phenotype, there are color changes related to worse disease prognosis.

Key words: dermatology, dogs, schnauzer, coat

A pigmentação individual dos pelos pode ser uniforme por todo o comprimento da haste ou pode variar. As células pigmentares no bulbo do pelo depositam pigmentos nas células corticais e medulares ou entre elas. A quantidade de pigmento depositado no pelo e sua localização produzem diferentes efeitos ópticos. Além disso, os melanócitos dos folículos podem ou não produzir pigmento durante o período de crescimento (SCOTT et al., 2001c).

A predileção de algumas raças por condições específicas de pele podem ajudar o reconhecimento de certas afecções (ROSENKRANTZ, 2010). Os cães da raça schnauzer são predispostos a desenvolver hipersensibilidade alérgica, síndrome do comedão do schnauzer, hipotiroidismo, dermatite necrolítica superficial e aurotriquia (ROSENKRANTZ, 2010).

Alterações adquiridas na coloração da pelagem de cães são raras (WHITE et al., 1992). Schnauzers jovens miniaturas podem apresentar desenvolvimento idiopático de coloração dourada do pelame, primariamente do tronco, chamada de aurotriquia (GORDON, 2004). A aurotriquia é uma doença de etiologia desconhecida (KALAHER, 2004; SCOTT et al., 2001b), que afeta principalmente a raça schnauzer miniatura, adultos jovens, sendo a localização mais comum nas áreas do tronco, periocular e orelha (KALAHER, 2004). Tendo em vista a restrição à raça schnauzer miniatura, acredita-se que exista alguma influência genética (SCOTT et al., 2001b).

Um cão da raça schnauzer, de três anos de idade, macho, foi atendido pelo Serviço de dermatologia veterinária da UNESP, campus de Botucatu, com histórico de alteração na coloração da pelagem há dez dias. $\mathrm{O}$ animal não apresentava nenhuma alteração sistêmica ou dermatológica além da alteração de coloração dos pelos, que se caracterizava por manchas no dorso, de, aproximadamente, quatro centímetros, de coloração amarelo brilhante, semelhante a ouro (Figura 1).

IFaculdade de Medicina Veterinária e Zootecnia (FMVZ), Universidade Estadual Paulista "Júlio de Mesquita Filho" (UNESP), 18618-970, Botucatu, SP, Brasil. E-mail: palumboma11@yahoo.com.br. *Autor para correspondência. 


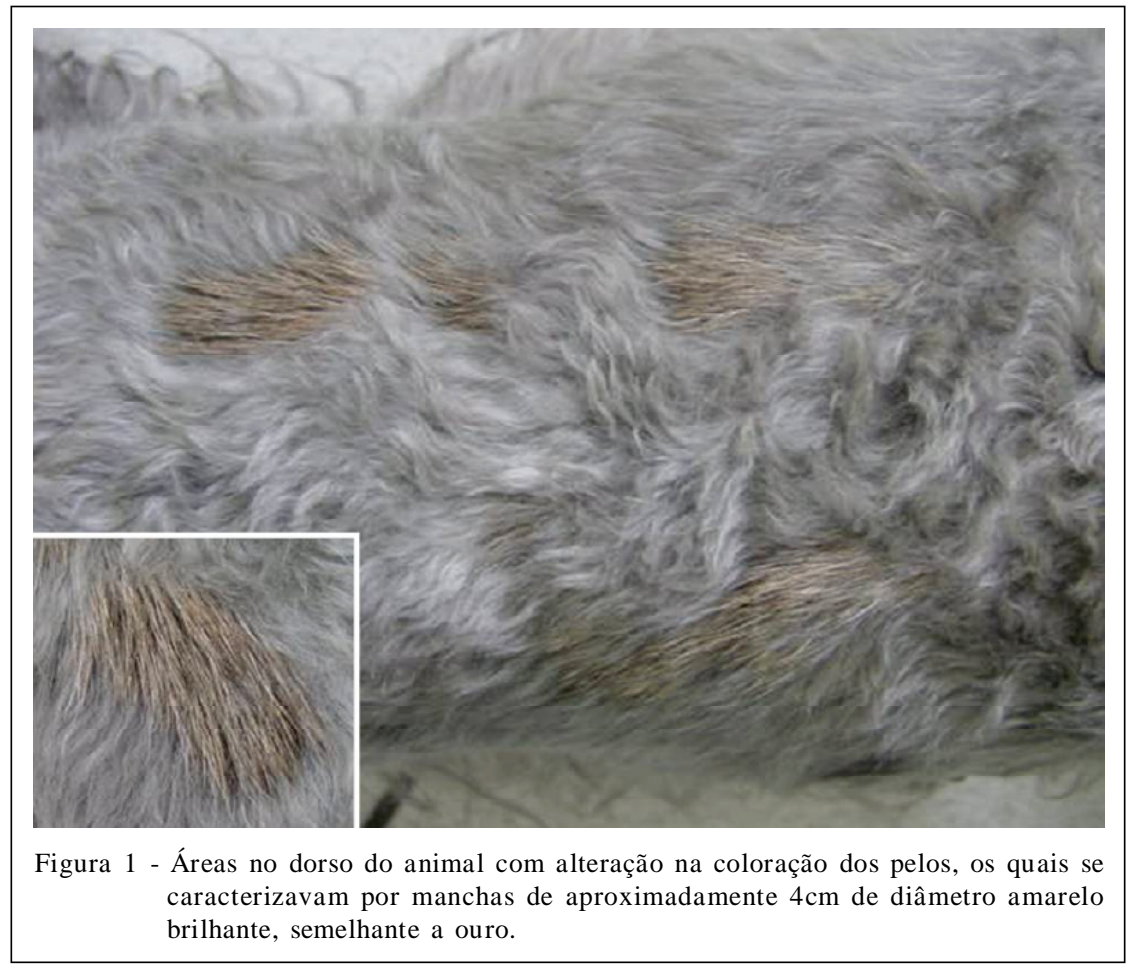

Foi realizado exame parasitológico de raspado cutâneo e cultura fúngica, que resultaram negativos. Também se realizou biópsia e exame histopatológico, os quais não apresentaram alterações morfológicas da pele. O tricograma, entretanto, revelou coloração amarelo brilhante em córtex e cutícula da haste dos pelos, confirmando o diagnóstico de aurotriquia (Figura 2). Alguns pelos em fase anágena, com coloração amarela em córtex e medula de hastes pilosas também foram encontrados. Como se tratava de

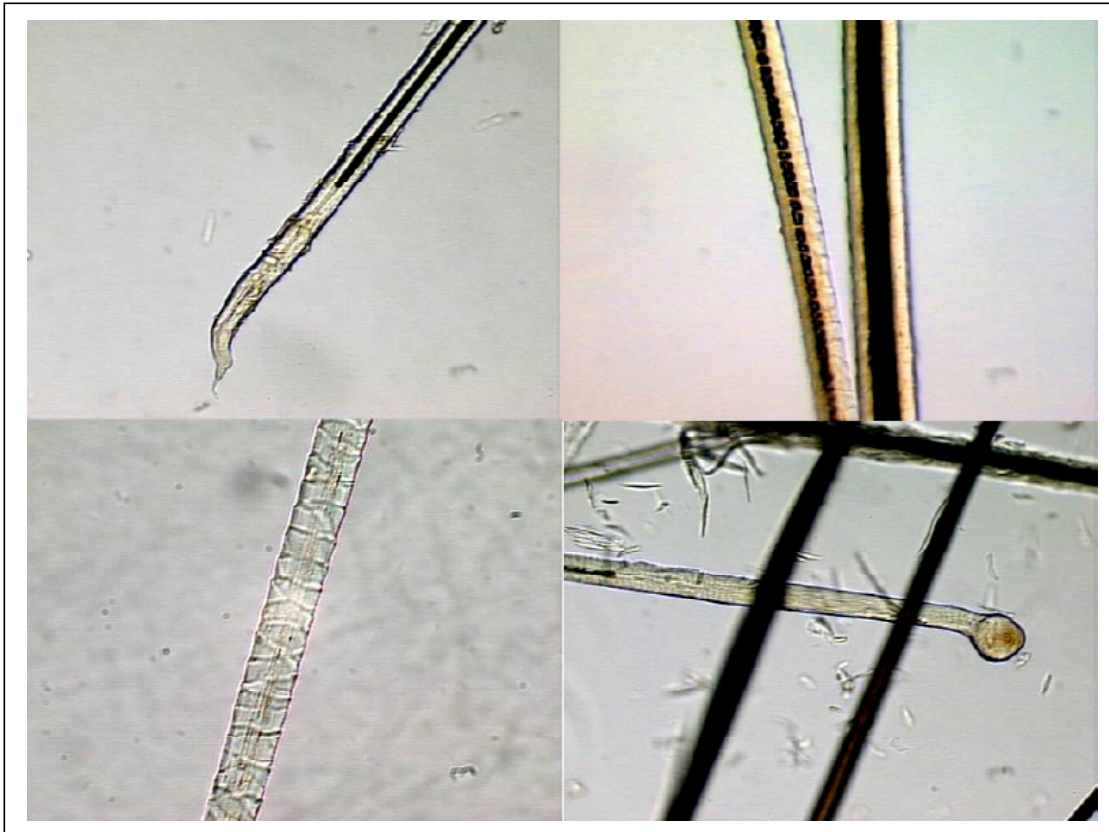

Figura 2 - Tricograma: presença de pelos de coloração amarelo brilhante em córtex e cutícula da haste dos pelos. 
alteração meramente estética, o proprietário foi instruído a apenas observar a evolução e manter retornos esporádicos. Após 20 meses, a coloração dos pelos voltou ao normal, sem a necessidade de tratamento.

Cães de ambos os sexos podem ser acometidos pela aurotriquia e o distúrbio é identificado em cães adultos jovens, tipicamente entre dois e três anos de idade (SCOTT et al., 2001b). A idade do animal deste relato foi semelhante à relatada por WHITE et al. (1992), que estudou 18 casos de aurotriquia em schnauzers miniaturas, e a média de idade encontrada foi dois anos e meio, sem predileção sexual. A alteração na coloração não foi relacionada com disfunção endócrina ou outros problemas de saúde (WHITE et al., 1992).

Os cães afetados apresentam tipicamente áreas desiguais de mudança de coloração dos pelos nas regiões do tórax e ao longo do abdome (LANE et al., 2007; ROSENKRANTZ, 2010), fato também observado neste caso. A coloração dourada, observada nos pelos afetados, corrobora os achados de SCOTT (2001b), KUSTRITZ (2006) e ROSENKRANTZ (2010). Em alguns casos, o quadro pode ser mais difuso e envolver a região peri auricular ou orelhas (SCOTT et al., 2001b; ROSENKRANTZ, 2010). Pode ser notado um afinamento do pelo nas áreas acometidas (SCOTT et al., 2001b). Os cães, por outro lado, são sadios. Afora algumas mudanças pigmentares nos pelos de guarda, não existe explicação histológica para esse amarelamento (SCOTT et al., 2001b).

Não foram encontrados relatos de aurotriquia em serem humanos. A principal forma de alteração da cor da haste pilosa em humanos é a leucotricose, em que ocorre o embranquecimento dos pelos devido à falta de formação de melanina pelos melanócitos da matriz do pelo, e pode ser congênita ou adquirida (SAMPAIO \& RIVITTI, 2007).

Nenhum tratamento é indicado ou efetivo para a aurotriquia (SCOTT et al., 2001b; ROSENKRANTZ, 2010), portanto, não foi instituída terapia neste caso. A resolução espontânea ocorreu em 20 meses, fato também observado por outros autores, que relataram melhora dos sinais clínicos em 6 a 24 meses (WHITE et al., 1992; KALAHER, 2004). Em um estudo realizado por WHITE et al. (1992), 55\% dos animais retornaram à coloração normal em 2 anos. Tanto a coloração como a densidade da pelagem retornam ao normal e as recidivas são raras (SCOTT et al., 2001b) e também não ocorreram neste caso. No trabalho realizado por WHITE et al. (1992), apenas um dos 18 animais com aurotriquia idiopática apresentou recidiva.
A alopecia canina recorrente dos flancos é uma doença caracterizada por alopecia estacional simétrica que afeta o tórax e o flanco dos animais acometidos e, quando o pelo volta a crescer, pode ser observada uma mudança na coloração da pelagem para mais clara (leucotriquia) ou mais escura (menalotriquia) e, em alguns animais, o pelo fica mais seco, áspero e quebradiço (PATEL et al., 2010). Como o animal do presente relato não apresentou alopecia anterior, a ocorrência dessa doença foi descartada.

A aurotriquia é uma enfermidade de caráter meramente estético, em que se alcança a remissão dos sintomas em alguns meses, sendo considerado problema apenas quando acomete animais de exposição, pois pode ser considerado fora do padrão da raça.

\section{REFERÊNCIAS}

GORDON, J.N. Depigmenting disorders. In: RHODES, K.H. The 5 minute veterinary consult clinical companion. Philadelphia: Williams \& Wilkins, 2004. p.138-143.

KALAHER, K.M. Alteraciones congênitas del desarrolo. In: MORGAN, R.V. et al. Clinica de pequeños animals. Madrid: Elsevier, 2004. p. 828-834.

KUSTRITZ, M.V.R. Known hereditary disease in dogs. In: The dog breeder's guide to successful breeding and health management. St Louis: Saunders Elsevier, 2006. p.411-436.

LANE, D.R. et al. Dictionary of veterinary nursing. Philadelphia: Elsevier, 2007. 87p.

PATEL, A. et al. Alopecia recorrente de los flancos canina. In: Dermatología de pequeños animales. Barcelona: Elsevier, 2010. p.150-153.

ROSENKRANTZ, W. Canine breed specific skin diseases. 2010. Acesso em: 05 abr. 2010. On line. Disponível em: <http:/ /www.michvma.org/documents/MVC\%20Proceedings\%202010/ rosenkrantz\%2004.pdf>.

SAMPAIO, S.A.P.; RIVITTI, E.A. Tricoses. In: Dermatologia. São Paulo: Artes médicas, 2007. p.419-439.

SCOTT, D.W. et al. Congenital and hereditary defects. In: Small animal dermatology. Philadelphia: Saunders, 2001a. p.913-1004.

SCOTT, D.W. et al. Pigmentary abnormalities. In: Small animal dermatology. Philadelphia: Saunders, $2001 \mathrm{~b}$. p.1005-1024.

SCOTT, D.W. et al. Structure and function of the skin. In: Small animal dermatology. Philadelphia: Saunders,

2001c. p.1-70.

WHITE, S.D. et al. Acquired aurotriquia ("Gliding syndrome") of miniature schnauzers. Veterinary Dermatology, v.3, n.1, p.37-42, 1992. 